\title{
Linking bacterial and eukaryotic microbiota to litter chemistry: Combining next generation sequencing with ${ }^{13} \mathrm{C}$ CPMAS NMR spectroscopy
}

\author{
Giuliano Bonanomi ${ }^{\mathrm{a}, \mathrm{b}, *}$, Francesca De Filippis ${ }^{\mathrm{a}, \mathrm{b}}$, Gaspare Cesarano ${ }^{\mathrm{a}}$, Antonietta La Storia ${ }^{\mathrm{a}}$, Maurizio Zotti ${ }^{\mathrm{a}}$, \\ Stefano Mazzoleni ${ }^{\mathrm{a}, \mathrm{b}}$, Guido Incertic \\ ${ }^{a}$ Department of Agricultural Sciences, University of Naples Federico II, Via Università 100, 80055, Portici, NA, Italy \\ ${ }^{\mathrm{b}}$ Task Force on Microbiome Studies, University of Naples Federico II, Naples, Italy \\ ${ }^{c}$ Di4A, Department of Agri-Food, Environmental and Animal Sciences, University of Udine, Via delle Scienze 206, 33100, Udine, Italy
}

\section{ARTICLE INFO}

\section{Keywords:}

$\mathrm{C} / \mathrm{N}$ microbiome

Lignin/N

Litter chemistry

Microbial diversity

Microbial succession

\begin{abstract}
A B S T R A C T
Microbial succession over decomposing litter is controlled by biotic interactions, dispersal limitation, grazing pressure, and substrate chemical changes. Recent evidence suggests that the changes in litter chemistry and microbiome during decomposition are interdependent. However, most previous studies separately addressed the microbial successional dynamics or the molecular changes of decomposing litter. Here, we combined litter chemical characterization by ${ }^{13} \mathrm{C}$ NMR spectroscopy with next generation sequencing to compare leaf litter chemistry and microbiome dynamics using 30 litter types, either fresh or decomposed for 30 and 180 days.

We observed a decrease of cellulose and $\mathrm{C} / \mathrm{N}$ ratio during decomposition, while lignin content and lignin/ $\mathrm{N}$ ratio showed the opposite pattern. ${ }^{13} \mathrm{C}$ NMR revealed significant chemical changes as microbial decomposition was proceeding, with a decrease in $O$-alkyl $\mathrm{C}$ and an increase in alkyl $\mathrm{C}$ and methoxyl $\mathrm{C}$ relative abundances. Overall, bacterial and eukaryotic taxonomical richness increased with litter age. Among Bacteria, Proteobacteria dominated all undecomposed litters but this group was progressively replaced by members of Actinobacteria, Bacteroidetes, and Firmicutes. Nitrogen-fixing genera such as Beijerinckia and Rhizobium occurred both in undecomposed as well as in aged litters. Among Eukarya, fungi belonging to the Ascomycota phylum were dominant in undecomposed litter with the typical phyllospheric genus Aureobasidium. In aged litters, phyllospheric species were replaced by zygomycetes and other ascomycetous and basidiomycetous fungi. Our analysis of decomposing litter highlighted an unprecedented, widespread occurrence of protists belonging to the Amebozoa and Cercozoa. Correlation network analysis showed that microbial communities are non-randomly structured, showing strikingly distinct composition in relation to litter chemistry. Our data demonstrate that the importance of litter chemistry in shaping microbial community structure increased during the decomposition process, being of little importance for freshly fallen leaves.
\end{abstract}

\section{Introduction}

Decomposition of leaf litter is a fundamental process for biogeochemical cycles in terrestrial ecosystems, controlling the formation of organic carbon $(\mathrm{C})$ and nutrient stocks and, then, affecting above- and below-ground ecosystem functioning and community composition. At global and regional scales, litter decomposition is primarily controlled by climatic factors such as temperature and water availability (Aerts, 1997), whereas at community level litter chemistry plays a pivotal role (Melillo et al., 1982; Cotrufo et al., 2013).
Leaf litter supports microbiome activity providing organic carbon and nutrients (Hättenschwiler et al., 2005). A large number of studies investigated the dynamic changes of bacterial and fungal community composition during decomposition of leaf litter (Hudson, 1968; Schneider et al., 2012; Purahong et al., 2016). Several mechanisms have been proposed to explain the observed community shifts, including inter-specific competition, dispersal limitation (Frankland, 1998), time constraints of fungal fruiting body development (Harper and Webster, 1964), grazing pressure of arthropods (Newell, 1984) and, most important, chemical changes of substrate during decomposition (Osono and Takeda, 2001; Rinkes et al., 2011). Similar to what has been described for animals and humans, where gut microbiome compo-

\footnotetext{
* Corresponding author. Department of Agricultural Sciences, University of Naples Federico II, Via Università 100, 80055, Portici, NA, Italy.

Email address: giuliano.bonanomi@unina.it (G. Bonanomi)
} 
sition is shaped by the dietary habits (e.g. Bäumler and Sperandio, 2016), the amount and quality of leaf litter play a key role in defining microbiome composition and functions. In this regard, it is crucial highlighting that heterotrophic microbes, by progressively exploiting leaf litter, continuously alter its molecular composition (Swift et al., 1979; Berg and McClaugherty, 2008) which, in turn, affects microbial turnover and community composition. For instance, the rapid disappearance of the so called "sugar fungi" replaced by cellulolytic and ligninolytic fungi, is a well-recognized successional pattern (Hudson, 1968; Frankland, 1998), associated with the depletion of labile C compounds driven by fast growing species during early decomposition. In this context, an accurate definition of litter chemistry is crucial to understand the connection and interdependence between litter type, decomposition and microbiome composition and dynamics (Bhatnagar et al., 2018).

Litter chemistry dramatically varies among species across and within ecosystems, depending on the plant functional type and leaf traits (Cornwell et al., 2008). Moreover, during microbial decomposition, mainly driven by fungi and bacteria, the chemistry of the organic substrate continuously changes. Different litter chemical fractions decompose at different rates, with the rapid depletion of labile $\mathrm{C}$ compounds leading to relative preservation of more recalcitrant compounds such as lignin (Berg and McClaugherty, 2008). Microbes progressively transform organic materials into novel recalcitrant materials that accumulate as decomposition proceeds (Preston et al., 2009). Historically, C/ $\mathrm{N}$ and lignin/ $\mathrm{N}$ ratios have been the most widely used indicators of litter chemistry (Melillo et al., 1982; Taylor et al., 1989). However, C/N and lignin/ $\mathrm{N}$ ratios can have limited usefulness to predict litter impact on different ecosystem functions, including litter mass loss (Bonanomi et al., 2011), phytotoxicity towards root proliferation (Mazzoleni et al., 2015), aggregate structural stability (Sarker et al., 2018), and suppression of plant pathogens (Bonanomi et al., 2018a). Searching for finer chemical predictors, several studies based on ${ }^{13} \mathrm{C}$-cross-polarization magic angle spinning nuclear magnetic resonance spectroscopy $\left({ }^{13} \mathrm{C}\right.$ NMR hereafter) clarified the major molecular changes experienced by ageing litter, including a rapid decrease of aminoacids, polypeptides, and $\mathrm{O}$-alkyl and di-O-alkyl $\mathrm{C}$ fractions corresponding to carbohydrates, and a relative enhancement of aliphatic $\mathrm{C}$ fraction, associated with microbial turnover, and aromatic, methoxyl and $\mathrm{N}$-alkyl C fractions diagnostic of lignin content (Kögel-Knabner, 2002).

Taken together, available evidence indicates that litter chemistry is likely a key driver of bacteria, fungal, and protist community dynamics. Indeed, a growing number of studies, based on molecular methods, have recently described the complex dynamics of bacterial and fungal communities that co-occur and functionally interact during litter decomposition (Schneider et al., 2012; Voříšková and Baldrian, 2013). However, the majority have separately addressed either the microbial successional dynamics, or the molecular changes of decomposing litter, while attempts to simultaneously target both topics over a wide range of litter types are still lacking. At most, some recent studies described the microbiome of one or few litter types (Purahong et al., 2016; Tláskal et al., 2016), as related to basic litter chemistry parameters (i.e. $\mathrm{C} / \mathrm{N}$ and lignin/ $\mathrm{N}$ ratios). Such approach based on classic chemical parameters does not allow an exhaustive description of the substrate molecular dynamics, which may limit the inference drawn from the experimental results. Aiming to overcome such limitations, we combined powerful organic chemistry and molecular biology tools with next generation sequencing to compare leaf litter chemistry and microbiome dynamics. In particular, we fully characterized the bacterial and fungal microbiomes and the relative abundance of $\mathrm{C}$ bond types in 10 litter types, either fresh or decomposed for 30 and 180 days. The main objectives of our study were: (i) to assess successional differences of microbial communities over different litter types;

(ii) to describe litter chemistry dynamics using advanced molecular techniques $\left({ }^{13} \mathrm{C} \mathrm{NMR}\right)$ as compared to basic parameters $(\mathrm{C} / \mathrm{N}$ and lignin/ $\mathrm{N}$ ratios);

(iii) to explore the inter-relationships between the molecular properties of decomposing litter and the successional dynamics of bacterial and fungal communities.

\section{Materials \& methods}

\subsection{Litter collection}

Ten plant species representing a wide range of litter quality were selected from Mediterranean and temperate ecosystems (Southern Italy): one grass (Festuca drymeia Mert \& W.D.J. Koch), one perennial forb (Acanthus mollis L), one evergreen shrub (Coronilla emerus L.), one vine (Hedera helix L), two evergreen trees (Pinus halepensis Mill. and Quercus ilex L.), and four deciduous trees (Fagus sylvatica L., Fraxinus ornus L., Populus nigra L., and Robinia pseudoacacia L.). Two species are nitrogen-fixing ( $C$. emerus and $R$. pseudoacacia). For each species, at least 15 individuals from natural communities were randomly selected at the sampling sites. Freshly abscised leaves were collected by placing nets under the plants, carried to the laboratory, dried (at $40^{\circ} \mathrm{C}$ until constant weight was reached) and stored in sealed plastic bags at room temperature. Considerable effort was made throughout sampling to ensure clean, uncontaminated leaf samples, including use of gloves during sample collection and decontamination of equipment prior to and during sampling.

\subsection{Litter decomposition experiment}

The decomposition experiment was performed in microcosms following the litterbag method (Berg and McClaugherty, 2008), under controlled, optimal conditions, to isolate the effect of litter quality on microbiome composition from those of fluctuating environmental conditions. In detail, large $\left(20 \times 20 \mathrm{~cm}^{2}\right)$ terylene litterbags (mesh size $1 \mathrm{~mm}$ ) were filled with $5 \mathrm{~g}$ of undecomposed, dry leaf litter and placed in plastic trays $(120 \times 120 \times 25 \mathrm{~cm})$. A microbial inoculum was prepared by mixing $90 \mathrm{~g}$ of sterile water with $10 \mathrm{~g}$ of a soil collected from the topsoil layer (depth 0 to $-10 \mathrm{~cm}$ ) of a mixed forest located on the south-eastern slope of Monte Vesuvius ( $40^{\circ} 48^{\prime} \mathrm{N}, 14^{\circ} 20^{\prime} \mathrm{E}$, altitude $80 \mathrm{~m}$ a.s.l.). The soil properties are reported in Supplementary Table S1. The inoculum was sprayed over litter-bags to enhance the decomposition process and reproduce the microbial community present at the beginning of decomposition. Microcosms were kept in a growth chamber under controlled temperature $\left(18 \pm 2{ }^{\circ} \mathrm{C}\right.$ night and $24 \pm 2{ }^{\circ} \mathrm{C}$ day) and weekly watered to field capacity with distilled water. At each harvesting date $(0$, 30 , and 180 days after the inoculum spraying), 10 litterbags (replicates) were collected. Bags were dried in the laboratory (at $40^{\circ} \mathrm{C}$ until constant weight was achieved) and the remaining material weighed. In this way, 30 organic materials (10 species at three sampling dates) with different ages were produced: fresh, undecomposed litter (thereafter indicated as 0 days) and litter decomposed for 30 or 180 days.

\subsection{Litter chemistry}

The 30 materials were chemically characterized by measuring total $\mathrm{C}$ and $\mathrm{N}$ contents (flash combustion of microsamples - $5 \mathrm{mg}$ of dry, pulverized litter - Elemental Analyser NA 1500 - Carlo Erba Strumentazione, Milan, Italy). The relative content of acid-detergent hydrolysable fraction (thereafter indicated as labile $\mathrm{C}$ ), proximate cellu- 
lose, and lignin were quantified with the procedure described by Gessner (2005). Shortly, labile C was determined by mild acid hydrolysis with $0.5 \mathrm{M} \mathrm{H}_{2} \mathrm{SO}_{4}$ and the detergent cetyltrimethylammonium $\left(20 \mathrm{gl}^{-1}\right)$. Proximate cellulose was determined as hydrolysable fraction after sulphuric acid treatment (loss due to $72 \% \mathrm{H}_{2} \mathrm{SO}_{4}$ for $3 \mathrm{~h}$ ), and proximate lignin as the unhydrolyzable fraction (loss upon ignition after the $\mathrm{H}_{2} \mathrm{SO}_{4}$ treatment). It is noteworthy that the lignin assessed with this method does not correspond to pure lignin because it includes some other hydrolysis-resistant organic compounds, such as waxes, cutin, as well as condensed tannins (Berg and McClaugherty, 2008). All fractions were presented as ash-free dry mass.

Spectral data from ${ }^{13} \mathrm{C}$ NMR in solid state were obtained under the same conditions in order to allow a quantitative comparison among spectra (Spectrometer Bruker AV-300 - Bruker Instrumental Inc, Billerica, MA, USA). Analytical setup included $4 \mathrm{~mm}$ wide-bore magic angle spinning (MAS) probe, MAS of rotor spin $13000 \mathrm{~Hz}$, recycle time $1 \mathrm{~s}$, contact time $1 \mathrm{~ms}$, acquisition time $20 \mathrm{~ms}, 2000$ scans, sample packed in 4-mm zirconium rotors with Kel-F caps (Wilmad/Lab Glass, Buena, NJ, USA), pulse sequence applied with a $1 \mathrm{H}$ ramp to account for non-homogeneity of the Hartmann-Hahn condition at high spin rotor rates. Each NMR spectrum was automatically integrated (iNMR software, www. inmr.net) to calculate the area of the peaks which appeared in the chosen region. Selection of spectral regions and identification of C-types were performed according to previous studies (Spaccini et al., 2000; Mathers et al., 2007; Bonanomi et al., 2015; Incerti et al., 2017). The following seven regions and $C$ types were considered: $0-45$ p.p.m $=$ alkyl C; $\quad 46-60 \mathrm{ppm}=$ methoxyl $\quad \mathrm{C} ; \quad 61-90 \mathrm{ppm}=O$-alkyl $\quad \mathrm{C}$; 91-110 ppm $=$ di-O-alkyl C; $111-140 \mathrm{ppm}=H-$ and $C$ - substituted aromatic C; $141-160$ ppm $O$-substituted aromatic C (phenolic and $O$-aryl C); 161-190ppm carboxylic C.

\subsection{DNA extraction and sequencing}

Total DNA extraction from litter samples was carried out by using the PowerSoil DNA Isolation kit (Mo Bio Laboratories Inc., Carlsbad, CA) according to the manufacturer's instructions. DNA extraction was carried out in triplicate for each litter type and the extraction product was then pooled before library preparation. Metagenomic analysis was done using a single litter sample for a total of 30 samples. Bacterial and eukaryotic diversity were assessed by pyrosequencing of the V1-V3 regions of the $16 \mathrm{~S}$ rRNA gene ( $\sim 520 \mathrm{bp})$ and a portion of the $18 \mathrm{~S}$ rRNA gene ( $\sim 36$ bp), respectively. Primers and PCR conditions were previously reported (Ercolini et al., 2012; De Filippis et al., 2017). PCR products were purified with the Agencourt AMPure kit (Beckman Coulter, Milan, IT) and quantified using a Plate Reader AF2200 (Eppendorf, Milan, IT). Equimolar pools were obtained prior to further processing and sequenced on a GS Junior platform (454 Life Sciences, Roche Diagnostics, IT), according to the manufacturer's instructions.

\subsection{Sequence data analysis}

Raw reads were filtered and analysed by using the QIIME 1.8.0 software (Caporaso et al., 2010). Reads shorter than 300 bp, with more than 1 primer mismatch and with average quality score lower than 25 were discarded. Operational Taxonomical Units (OTUs) defined at $97 \%$ of sequence similarity were picked through de novo approach and uclust method and taxonomic assignment was obtained by using the RDP classifier and the Greengenes (McDonald et al., 2012) or the Silva SSU/LSU rRNA gene database release 119 (Quast et al., 2012). Chloroplast and Streptophyta contamination, as well as singleton OTUs, were removed and the relative abundance of other taxa was recalculated. In order to avoid biases due to the different sequencing depth, OTU tables were rarefied to the lowest number of sequences per sample (3303 and 2660 for Bacteria and Eukarya, respectively).
The 16S and 18S rRNA gene sequences are available at the Sequence Read Archive (SRA) of the National Center for Biotechnology Information (NCBI), under accession number SRP151263.

\subsection{Data analysis}

Statistical analyses and plotting were carried out in $\mathrm{R}$ environment (http://www.r-project.org) and with Statistica 10.0 (STATSOFT, TULSA, OK). Alpha-diversity analysis was carried out in QIIME on rarefied OTU tables, calculating Chao's 1 estimator and Shannon's index (H). Data normality was checked by Shapiro-Wilk test (Supplementary Table S2).

Generalized Linear Mixed Models (GLMMs) were used to assess main and second order effects of litter species (treated as a random effect) and age (treated as a continuous covariate) on OTU relative abundance and alpha diversity parameters. Pairwise differences were tested for statistical significance using Duncan's post-hoc test at $\mathrm{P}<0.05$. Heatplots were generated by made $4 \mathrm{R}$ package using hierarchical Ward-linkage clustering based on the Spearman's correlation matrix of bacterial or eukaryotic taxa abundances.

Non-metric multidimensional scaling (NMDS) was carried out using the metaMDS function (vegan package) on a Bray-Curtis dissimilarity matrix calculated on bacterial or fungal genera abundance. Leaf litter chemical parameters were fitted to the NMDS ordination plots using the envfit function (vegan package). Spearman's pairwise correlations were computed between bacterial or eukaryotic phyla abundance and litter quality parameters (corr.test function in psych package). Correction of p-values for multiple testing was performed when necessary (Benjamini and Hochberg, 1995). Statistically significant correlation scores were visualized in a network using Cytoscape v. 3.4.0 (http://www.cytoscape. org), with nodes representing bacterial and eukaryotic phyla and litter elemental, proximate, and ${ }^{13} \mathrm{C}$ NMR-based chemical traits.

\section{Results}

\subsection{Litter mass loss and associated chemistry}

Litter mass loss varied among litter types, and for all species, over decomposition time (Fig. 1). Mass loss was initially very rapid for $A$. mollis, C. emerus, H. helix, and F. ornus, and slower for Q. ilex, F. sylvatica, and $P$. halepensis, showing intermediate values for $P$. nigra, $R$. pseudoacacia and F. drymeia. However, as decomposition was proceeding, mass loss progressively declined for all litters, especially for A. mollis, C. emerus, and H. helix.

$\mathrm{C} / \mathrm{N}$ and lignin/ $\mathrm{N}$ ratios largely varied among undecomposed litters (Fig. 2, Table 1). Expectedly, C/N ratio significantly decreased with litter age for all materials (ANOVA; $\mathrm{P}<0.05$ ), with the exception of $A$.

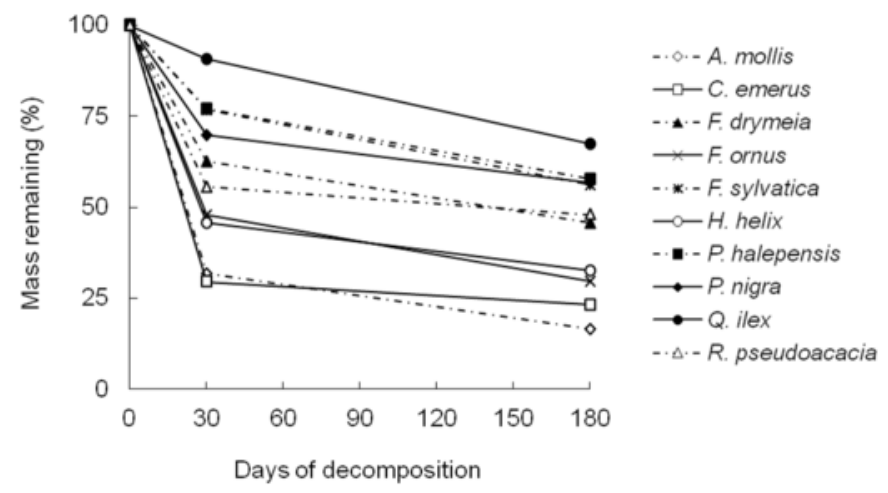

Fig. 1. Dynamics of litter mass remaining during 180 days of decomposition. Data refer to mean of 10 replicates for each species. 

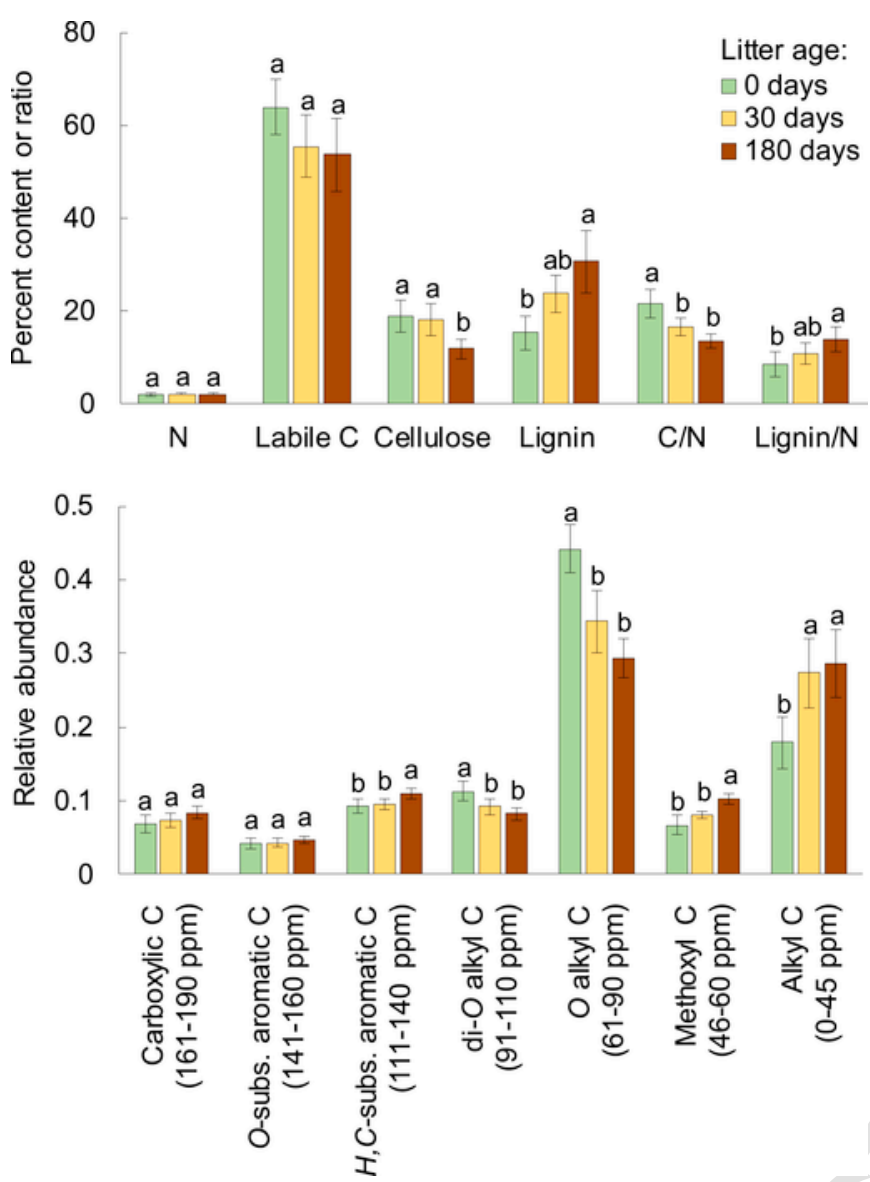

Fig. 2. Dynamics of litter nitrogen (N), labile C, cellulose and lignin percent content, C/N and lignin/N ratios (top), and C-types corresponding to ${ }^{13} \mathrm{C}$ CPMAS NMR regions (bottom) during 180 days of decomposition. Data refer to mean of 10 litter species \pm SD. Different letters within each chemical descriptor indicate age-dependent significant differences (Duncan test from one-way ANOVA at $P<0.05$ ).

mollis, while lignin/ $\mathrm{N}$ ratio consistently increased in all litter species. Litter $\mathrm{N}$ and lignin concentration changed during decomposition and with plant species, generally increasing with litter age. Differently, cellulose content mostly decreased with litter age, with higher rates in the cases of F. drymeia, H. helix, and Q. ilex.

${ }^{13} \mathrm{C}$ NMR spectra revealed significant and consistent differences among litter species, as well as changes in the relative abundance of different $\mathrm{C}$ types during decomposition (Table 1 ). Fresh litter chemistry largely varied among species, with relative abundance of $O$-alkyl-C and di-O-alkyl-C fractions, which correspond to sugars and polysaccharides, decreasing during the first 30 days of decomposition. On the other hand, the relative content of aliphatic alkyl-C, characteristic of lipid waxes, cutins and microbial by-products, increased during the first 30 days, particularly in litters of A. mollis, C. emerus, F. drymeia, H. helix, and P. nigra, then showing at most a slight increase at later stage. The relative abundance of aromatic $\mathrm{C}$ did not change substantially throughout the observation period, with the exception of $H$ - and $\mathrm{C}$-substituted $\mathrm{C}$ that showed a slight, but significant increase in the most aged materials. A late increase was also observed for methoxyl C. Finally, the relative content of the carboxylic $C$ fraction did not vary significantly with litter age, showing limited changes of different sign in different materials.

\subsection{Microbiome diversity}

Litter age showed significant enhancing effects on OTU number and microbial diversity (Table 2; Fig. 3), although with different magnitude for bacterial and eukaryotic communities. In all cases, bacterial and eukaryotic diversity was higher in litter decomposed for 180 days compared to fresh materials ( $\mathrm{P}<0.05$; Table S3). However, OTU number and microbial diversity largely varied among litter species (Supplementary Fig. S1). In particular, a remarkable increase in bacterial OTUs with litter age was observed for $F$. drymeia, $P$. halepensis and $P$. nigra litters, while the same pattern in eukaryotic diversity was most evident for F. sylvatica and R. pseudoacacia litters. Much more rarely, OTUs number and microbial diversity decreased during decomposition, as in the case of Bacteria in R. pseudoacacia litter.

\subsection{Bacterial succession}

An overview of bacterial succession is reported in Fig. 4. Proteobacteria dominated on undecomposed litter (mean \pm standard error of relative abundance was $83.0 \pm 2.6 \%$ ), followed by Actinobacteria, Bacteroidetes and Firmicutes $(9.2 \pm 2.7 \%, 3.9 \pm 0.8 \%$ and $2.7 \pm 0.8 \%)$. As decomposition was proceeding, Proteobacteria were largely substituted by Firmicutes. Actinobacteria and Bacteroidetes generally increased with litter age, but the response was litter species-specific. For instance, Bacteroidetes thrived in 180-day old litter of $F$. drymeia (relative abundance $36.0 \%$ ), but were not found in F. sylvatica material. Firmicutes dominated in aged litters of F. sylvatica (80.1\%), Q. ilex $(79.4 \%)$ and C. emerus (68.9\%) but were relatively rare in $F$. ornus $(12.5 \%)$ and H. helix litters (18.5\%). Minor contributing phyla, such as Gemmatimonadetes, Chloroflexi, Planctomycetes and others mostly appeared in litter decomposed for 180 days. These phyla showed relative abundance $<5 \%$ in most materials, with the exception of $P$. nigra litter (overall $21.4 \%$ ), where Chloroflexi, mostly absent elsewhere, were the major contributors (5.7\%).

Considering the most abundant genera (i.e. relative abundance $>1 \%$ in at least one litter sample), the majority showed a significant abundance shift during the decomposition process (Fig. S2). For instance, members of Sphingomonas and Pseudomonas that were very abundant in undecomposed litter became progressively rarer during decomposition, being replaced by Streptomyces, Bacillus and Paenibacillus. In this regards, both NMDS (Fig. 5) and hierarchical Ward clustering (Fig. S3) based on microbial composition at genera and family levels, respectively, showed a clear separation of the samples according to litter age.

\subsection{Eukarya succession}

As for prokaryotes, Fig. 4 shows eukaryotic successional pattern during litter decomposition. Members of the phylum Ascomycota dominated the eukaryotic community of all undecomposed litter materials (mean \pm standard error of relative abundance $86.6 \pm 2.5 \%$ ). In some litter samples, however, other Eukarya were relatively abundant, as in the case of protozoans belonging to the Apicomplexa in C. emerus litter (21.4\%) and members of Zygomycota in P. nigra litter (7.8\%). During decomposition, Ascomycota abundance rapidly decreased after 30 days $(50.0 \pm 7.0 \%)$, remaining constant up to 180 days $(49.9 \pm 8.5 \%)$. Members of the polyphyletic phylum Zygomycota were rare in fresh litter $(1.0 \pm 0.7 \%)$, but underwent a dramatic increase after 30 days of decomposition $(24.9 \pm 7.6 \%)$ especially in $F$. sylvativa $(62.1 \%), P$. nigra (56.2\%), Q. ilex (43.5\%), and F. drymeia (41.2\%) litters. After 180 days, Zygomycota were still relatively abundant only in $F$. sylvatica (29.1\%) and P. nigra (27.2\%) litters, being much rarer $(1.4 \pm 0.4 \%)$ in all other materials. Members of Amoebozoan, Basidiomycota and Cercozoa were substantially absent in fresh litters $(0.1 \pm 0.1 \%, 0.2 \pm 0.1 \%$ and $0.3 \pm 0.2 \%$, respectively), but more abundant in aged materials. Amoebozoan peaked after 30 days of decomposition $(8.7 \pm 3.1 \%)$, decreasing later on $(4.0 \pm 1.8 \%)$, while Basidiomycota were progressively more abundant in aged litters $(1.0 \pm 0.3 \%$ and 
Table 1

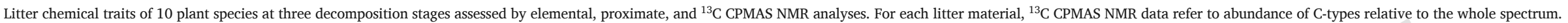

\begin{tabular}{|c|c|c|c|c|c|c|c|c|c|c|c|c|c|}
\hline \multirow[t]{2}{*}{ Species } & \multicolumn{6}{|c|}{ Elemental and proximate parameters } & \multicolumn{5}{|c|}{${ }^{13} \mathrm{C}$-CPMAS NMR-derived parameters } & \\
\hline & $\begin{array}{l}\text { Labile } \\
\text { C (\%) }\end{array}$ & $\begin{array}{l}\text { Cellulose } \\
(\%)\end{array}$ & $\begin{array}{l}\text { Lignin } \\
(\%)\end{array}$ & $\begin{array}{l}\mathrm{N} \\
(\%)\end{array}$ & $\mathrm{C} / \mathrm{N}$ & Lignin/N & $\begin{array}{l}\text { Carboxylic C- } \\
161-190 \mathrm{ppm}\end{array}$ & $\begin{array}{l}\text { O-substituted aromatic C - } \\
141-160 \mathrm{ppm}\end{array}$ & $\begin{array}{l}\text { H-C-substituted aromatic C - } \\
111-140 \mathrm{ppm}\end{array}$ & $\begin{array}{l}\text { di-O-alkyl C - } \\
91-110 \text { ppm }\end{array}$ & $\begin{array}{l}\text { O-alkyl C - } \\
61-90 \text { ppm }\end{array}$ & $\begin{array}{l}\text { Methoxyl C - } \\
46-60 \mathrm{ppm}\end{array}$ & $\begin{array}{l}\text { Alkyl C - } \\
0-45 \mathrm{ppm}\end{array}$ \\
\hline A. mollis - 0d & 79.65 & 4.91 & 12,44 & 3,12 & 14.10 & 3.98 & 0.10 & 0.02 & 0.07 & 0.09 & 0.42 & 0.09 & 0.22 \\
\hline A. mollis - $30 \mathrm{~d}$ & 76.45 & 5.82 & 14.73 & 2.79 & 15.41 & 5.27 & 0.10 & 0.03 & 0.10 & 0.06 & 0.22 & 0.09 & 0.39 \\
\hline A. mollis - $180 \mathrm{~d}$ & 79.19 & 4.32 & 13.49 & 2.13 & 19.71 & 6.33 & 0.10 & 0.04 & 0.10 & 0.07 & 0.25 & 0.09 & 0.34 \\
\hline C. emerus - $0 \mathrm{~d}$ & 80.70 & 10.22 & 7.91 & 2.89 & 12.74 & 2.82 & 0.10 & 0.03 & 0.08 & 0.09 & 0.41 & 0.09 & 0.21 \\
\hline C. emerus - $30 \mathrm{~d}$ & 77.96 & 7.50 & 12.57 & 2.24 & 11.67 & 5.62 & 0.08 & 0.06 & 0.11 & 0.08 & 0.27 & 0.08 & 0.31 \\
\hline $\begin{array}{l}\text { C. emerus - } \\
180 \mathrm{~d}\end{array}$ & 79.38 & 8.46 & 10.55 & 2.07 & 10.06 & 5.10 & 0.10 & 0.04 & 0.10 & 0.05 & 0.23 & 0.12 & 0.37 \\
\hline F. drymeja - 0d & 53.01 & 26.96 & 16.15 & 1.70 & 26.52 & 9.50 & 0.04 & 0.04 & 0.12 & 0.18 & 0.62 & 0.00 & 0.00 \\
\hline $\begin{array}{l}\text { F. drymeja - } \\
\quad 30 \mathrm{~d}\end{array}$ & 46.14 & 22.78 & 24.06 & 1.74 & 22.25 & 13.83 & 0.05 & 0.04 & 0.09 & 0.12 & 0.49 & 0.07 & 0.15 \\
\hline $\begin{array}{l}\text { F. drymeja - } \\
180 \mathrm{~d}\end{array}$ & 46.12 & 13.52 & 28.56 & 1.87 & 12.86 & 15.31 & 0.07 & 0.04 & 0.12 & 0.10 & 0.37 & 0.10 & 0.21 \\
\hline F. ornus - $0 \mathrm{~d}$ & 74.08 & 15.54 & 10.02 & 1.65 & 27.18 & 6.09 & 0.06 & 0.03 & 0.08 & 0.11 & 0.46 & 0.07 & 0.20 \\
\hline F. ornus $-30 \mathrm{~d}$ & 57.91 & 22.61 & 18.27 & 2.29 & 14.93 & 8.00 & 0.06 & 0.04 & 0.09 & 0.12 & 0.43 & 0.07 & 0.19 \\
\hline F. ornus $-180 \mathrm{~d}$ & 62.12 & 15.35 & 20.13 & 2.05 & 15.14 & 9.82 & 0.08 & 0.05 & 0.11 & 0.09 & 0.29 & 0.11 & 0.27 \\
\hline F. sylvatica-0d & 55.69 & 21.22 & 22.48 & 2.07 & 18.96 & 10.89 & 0.07 & 0.06 & 0.11 & 0.12 & 0.41 & 0.07 & 0.16 \\
\hline $\begin{array}{l}\text { F. sylvatica - } \\
30 \mathrm{~d}\end{array}$ & 41.06 & 22.92 & 35.19 & 2.37 & 14.99 & 14.85 & 0.08 & 0.05 & 0.10 & 0.10 & 0.35 & 0.09 & 0.23 \\
\hline $\begin{array}{l}\text { F. sylvatica - } \\
180 \mathrm{~d}\end{array}$ & 41.10 & 18.82 & 39.00 & 2.46 & 12.23 & 15.89 & 0.09 & 0.05 & 0.12 & 0.09 & 0.31 & 0.11 & 0.23 \\
\hline H. helix - od & 70.46 & 23.63 & 5.77 & 2.00 & 22.56 & 2.89 & 0.07 & 0.03 & 0.06 & 0.09 & 0.43 & 0.07 & 0.25 \\
\hline H. helix $-30 \mathrm{~d}$ & 64.42 & 13.59 & 20.47 & 2.54 & 19.06 & 8.07 & 0.06 & 0.02 & 0.06 & 0.07 & 0.28 & 0.07 & 0.45 \\
\hline H. helix - 180d & 60.52 & 10.91 & 26.49 & 1.82 & 16.98 & 14.55 & 0.07 & 0.03 & 0.08 & 0.06 & 0.21 & 0.07 & 0.49 \\
\hline $\begin{array}{l}\text { P. halapensis - } \\
\quad 0 \mathrm{~d}\end{array}$ & 45.64 & 23.74 & 30.28 & 1.50 & 26.77 & 20.25 & 0.04 & 0.05 & 0.09 & 0.11 & 0.44 & 0.07 & 0.21 \\
\hline $\begin{array}{l}\text { P. halapensis - } \\
30 \mathrm{~d}\end{array}$ & 44.24 & 19.56 & 35.65 & 1.95 & 21.13 & 18.28 & 0.05 & 0.05 & 0.10 & 0.11 & 0.40 & 0.07 & 0.21 \\
\hline $\begin{array}{l}\text { P. halapensis - } \\
180 \mathrm{~d}\end{array}$ & 37.32 & 16.52 & 45.17 & 2.12 & 12.83 & 21.31 & 0.06 & 0.06 & 0.12 & 0.10 & 0.36 & 0.10 & 0.20 \\
\hline P. nigra $-0 \mathrm{~d}$ & 61.46 & 22.49 & 12.51 & 1.53 & 25.01 & 8.20 & 0.07 & 0.05 & 0.11 & 0.12 & 0.43 & 0.06 & 0.16 \\
\hline P. nigra $-30 \mathrm{~d}$ & 49.64 & 26.43 & 18.79 & 2.03 & 17.21 & 9.28 & 0.08 & 0.05 & 0.10 & 0.09 & 0.33 & 0.08 & 0.28 \\
\hline P. nigra $-180 \mathrm{~d}$ & 47.80 & 11.50 & 31.22 & 2.24 & 12.03 & 13.94 & 0.08 & 0.04 & 0.11 & 0.08 & 0.30 & 0.11 & 0.29 \\
\hline Q. ilex $-0 \mathrm{~d}$ & 58.47 & 22.74 & 18.39 & 1.39 & 28.98 & 13.23 & 0.04 & 0.06 & 0.11 & 0.12 & 0.43 & 0.07 & 0.17 \\
\hline Q. ilex $-30 \mathrm{~d}$ & 47.23 & 23.80 & 28.31 & 1.79 & 18.91 & 15.86 & 0.07 & 0.05 & 0.10 & 0.10 & 0.38 & 0.08 & 0.22 \\
\hline Q. ilex $-180 \mathrm{~d}$ & 41.13 & 7.79 & 50.13 & 2.22 & 14.59 & 22.58 & 0.08 & 0.06 & 0.13 & 0.09 & 0.33 & 0.11 & 0.21 \\
\hline $\begin{array}{l}\text { R. pseudoacacia } \\
\quad-0 \mathrm{~d}\end{array}$ & 61.99 & 18.72 & 18.99 & 2.64 & 13.43 & 7.21 & 0.09 & 0.05 & 0.09 & 0.10 & 0.37 & 0.08 & 0.21 \\
\hline $\begin{array}{l}\text { R. pseudoacacia } \\
-30 \mathrm{~d}\end{array}$ & 51.42 & 17.39 & 30.42 & 2.73 & 11.15 & 11.16 & 0.10 & 0.04 & 0.10 & 0.07 & 0.28 & 0.10 & 0.30 \\
\hline $\begin{array}{l}\text { R. pseudoacacia } \\
-180 \mathrm{~d}\end{array}$ & 43.47 & 12.75 & 42.48 & 2.84 & 9.36 & 14.96 & 0.11 & 0.05 & 0.11 & 0.09 & 0.28 & 0.11 & 0.25 \\
\hline
\end{tabular}


Table 2

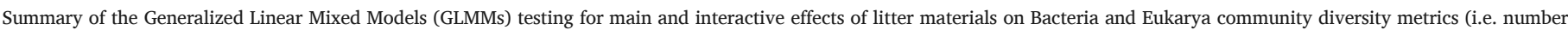

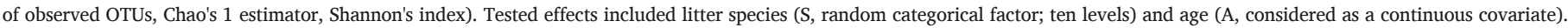
Significant $P$-values are in bold type.

\begin{tabular}{|c|c|c|c|c|c|c|c|c|c|c|c|c|c|}
\hline \multicolumn{7}{|l|}{ Bacteria } & \multicolumn{7}{|c|}{ Eukarya } \\
\hline & Effect type & SS & df & MS & $F$ & $P$ & & Effect type & SS & $\mathrm{df}$ & MS & $F$ & $P$ \\
\hline \multicolumn{14}{|c|}{$N$ of OTUs } \\
\hline S & Random & 21750.5 & 9 & 2416.7 & 0.76 & 0.6578 & $\mathrm{~S}$ & Random & 4359.4 & 9 & 484.4 & 0.31 & 0.9524 \\
\hline A & Fixed & 25671.0 & 1 & 25671.0 & 19.00 & 0.0018 & A & Fixed & 7698.2 & 1 & 7698.2 & 20.93 & 0.0013 \\
\hline $\mathrm{S} \times \mathrm{A}$ & Random & 12157.2 & 9 & 1350.8 & 0.42 & 0.8948 & $\mathrm{~S} \times \mathrm{A}$ & Random & 3309.8 & 9 & 367.8 & 0.24 & 0.9792 \\
\hline \multicolumn{14}{|c|}{ Chao's 1 estimator } \\
\hline S & Random & 69505 & 9 & 7723 & 0.65 & 0.7344 & $\mathrm{~S}$ & Random & 20768 & 9 & 2308 & 0.47 & 0.8642 \\
\hline A & Fixed & 252392 & 1 & 252392 & 33.20 & 0.0003 & A & Fixed & 33662 & 1 & 33662 & 19.14 & 0.0018 \\
\hline $\mathrm{S} \times \mathrm{A}$ & Random & 68423 & 9 & 7603 & 0.64 & 0.7419 & $\mathrm{~S} \times \mathrm{A}$ & Random & 15827 & 9 & 1759 & 0.36 & 0.9310 \\
\hline \multicolumn{14}{|c|}{ Shannon's index } \\
\hline S & Random & 4.57 & 9 & 0.51 & 0.39 & 0.9160 & $\mathrm{~S}$ & Random & 4.83 & 9 & 0.54 & 0.33 & 0.9456 \\
\hline A & Fixed & 3.09 & 1 & 3.09 & 7.93 & 0.0202 & $\mathrm{~A}$ & Fixed & 3.90 & 1 & 3.90 & 8.34 & 0.0180 \\
\hline $\mathrm{S} \times \mathrm{A}$ & Random & 3.51 & 9 & 0.39 & 0.30 & 0.9594 & $\mathrm{~S} \times \mathrm{A}$ & Random & 4.21 & 9 & 0.47 & 0.29 & 0.9632 \\
\hline
\end{tabular}

$5.0 \pm 2.6 \%$ in 30 - and 180-day old samples, respectively), showing highest abundance in H. helix (25.6\%) and F. ornus (14.9\%). Such trend was even more evident for Cercozoa $(6.8 \pm 3.7 \%$ and $24.6 \pm 7.8 \%$ in 30 and 180-day old litters, respectively), which became the dominant group in aged litter of the nitrogen-fixing species C. emerus $(87.7 \%)$ and R. pseudoacacia (35.7\%).

Most of the abundant Eukarya genera (i.e. relative abundance $>1 \%$ in at least one litter sample), similarly to what observed for Bacteria, showed a shift of relative abundance during decomposition (Fig. S4). Among Fungi, members of Aureobasidium were the dominant group in fresh litter, while at intermediate decomposition stage (30 days) Rhizopus and Rhizomucor, two members of the Zygomycota phylum, showed the highest relative abundance. At the latest stage (180 days) fungi belonging to Aspergillus and Coprinopsis, two genera of Ascomycota and Basidiomycota, respectively, were the most abundant (Fig. S4). NMDS (Fig. 5) and hierarchical and Ward clustering (Fig. S5), based on Eukarya composition at genus and family levels, respectively, clearly showed the importance of decomposition time in shaping the microbial community.

\subsection{Linking microbial succession to litter chemistry}

Correlation networks between litter microbiota and chemical traits provided a synthetic picture of the interdependence of microbial community composition and litter chemistry, as related to leaf type and age (Fig. 6). In undecomposed materials, the large predominance of Proteobacteria was positively associated with the substrate $\mathrm{C} / \mathrm{N}$ ratio, cellulose content, relative fraction of $O$-alkyl C and, to a lesser extent, Alkyl C (Fig. 6A). Proteobacteria abundance was also negatively associated with litter $\mathrm{N}$ content, carboxylic and methoxyl C fractions (Fig. 6B). A similar pattern of association was found for Actinobacteria, although with no link to Alkyl C, while the abundance of Bacteroidetes was positively associated to the cellulose content and negatively to the labile $\mathrm{C}$ content and the carboxylic $\mathrm{C}$ fraction. Firmicutes showed an opposite pattern, with positive associations with litter $\mathrm{N}$ content and methoxyl $\mathrm{C}$ fraction, and negative correlation with the cellulose content and $\mathrm{C} / \mathrm{N}$ ratio. In the same undecomposed materials, correlation networks for Eukarya showed less consistent association patterns. The ubiquitous dominance of Ascomycota included genera positively associated with lignin/ $\mathrm{N}$ ratio and carboxylic $\mathrm{C}$ fraction, and others negatively correlated with $\mathrm{C} / \mathrm{N}$ ratio, labile $\mathrm{C}$ content, and methoxyl $\mathrm{C}$ fractions. Associations of Ascomycota with lignin content and $O$-alkyl $\mathrm{C}$ fraction included both positive and negative cases, likely indicating different feeding preferences within this phylum. Other cases of significant associations included Cercozoa, positively correlated with litter $\mathrm{H}, \mathrm{C}$ - aromatic C fractions, and Zygomycota and Amoebozoa, negatively related with litter Alkyl C fraction and N content, respectively (Fig. 5B). Interestingly, genera from Apicomplexa, relatively abundant in undecomposed litter (Fig. 4), were not associated with litter chemical traits considered in our analysis.

The number of significant associations between litter microbiota and chemical traits dramatically increased after 30-days of decomposition. The number of genera correlated with specific litter traits (i.e. edge line width in Fig. 6) increased following the general increase of bacterial and eukaryotic diversity (i.e. node size in Fig. 6). But more interestingly, the number of litter chemistry parameters associated to microbiota (i.e. number of nodes in Fig. 6) increased as well. In particular, the increased number of taxa within all bacterial phyla, as well as the appearance of SAR super-group among Eukarya, not only reinforced the connections described above for undecomposed materials, but also corresponded to new relationships, as those with litter di-O-alkyl C and $O$-aromatic C fractions. Finally, after 180 days of decomposition, correlation networks generally showed fewer significant associations compared to less decomposed materials, indicating a lower litter chemistry-dependence of microbial community composition, and hence a higher compositional stability of bacterial and eukaryotic assemblages, compared to the preceding successional stages.

\section{Discussion}

\subsection{Bacterial and eukarya diversity}

Overall, we found a general increase in bacterial and eukaryotic taxonomical richness and diversity during decomposition, with the most relevant step corresponding to the early litter decay phase and a slight, but further increase at later stages. Similar results were reported by other culture-independent studies, showing a higher bacterial and fungal diversity in aged compared to fresh litter (Vořišková and Baldrian, 2013; Purahong et al., 2016; Tláskal et al., 2016). The progressive increase in microbial diversity over decomposition time is commonly explained with the rapid replacement of part of the phyllospheric community by more competitive saprotrophic bacteria and fungi. Thereafter, different highly diverse saprotrophic communities can co-exist as a consequence of the trophic specialization that follows the increase in litter chemical diversity occurring during decomposition, coupled to structural heterogeneity and the formation of microhabitats within the litter layer (Gartner and Cardon, 2004).

\subsection{Bacterial successional dynamics}

At phylum level, our multispecies experiment revealed similar successional trajectories among Bacteria. Firstly, we found that Proteobac- 

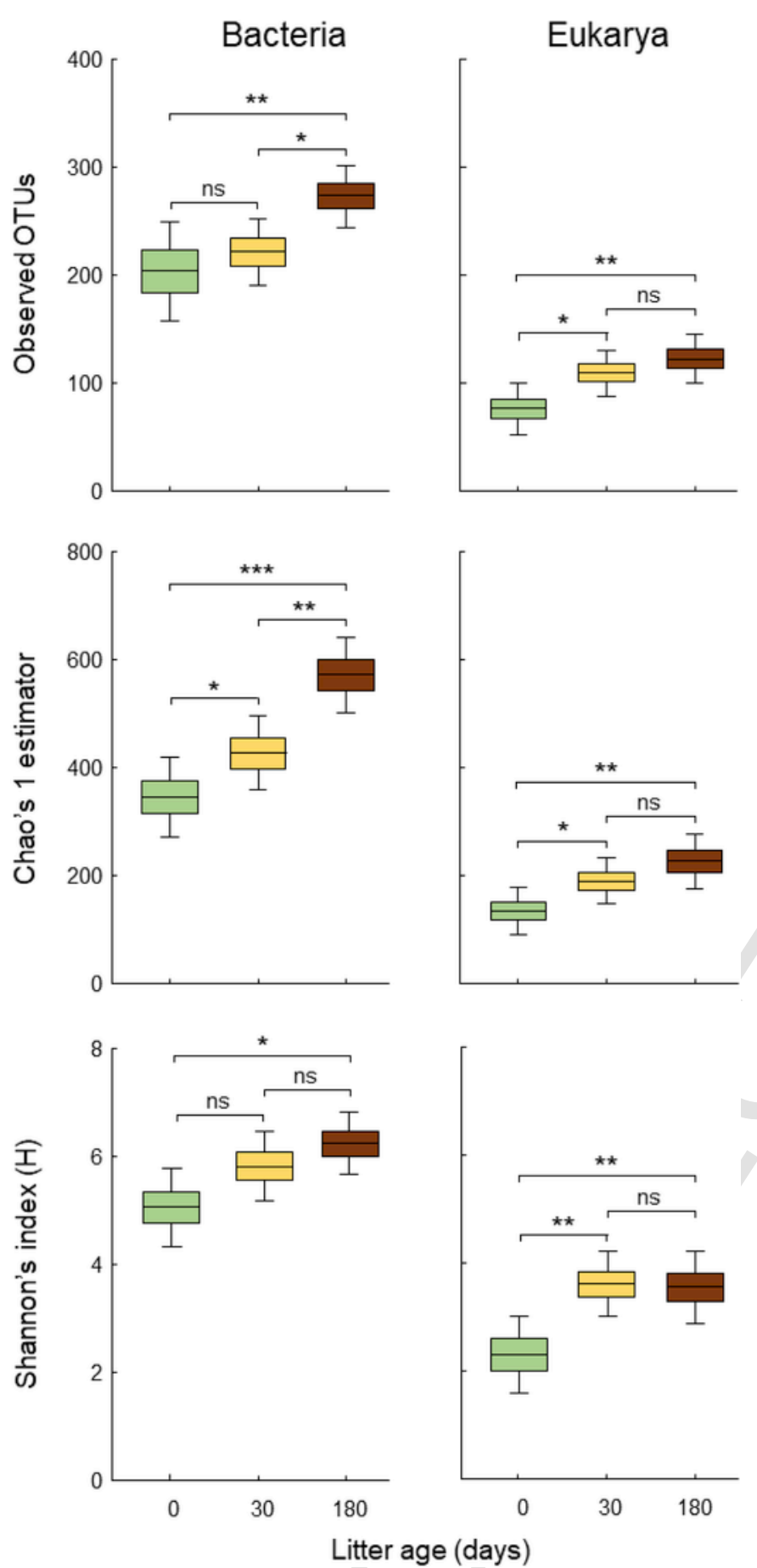

Fig. 3. Number of observed OTUs, Chao's 1 diversity estimator and Shannon's index of Bacteria (left) and Eukarya (right) communities in litter materials of different ages. Within each panel, boxplot data refer to mean (line), standard error (box) and 95\% confidence interval (whisker) of 10 litter materials at each litter age, with age-dependent differences indicated according to statistical significance $(* * *, P<0.01 ; * *, P<0.01 ; *, \mathrm{P}<0.05$; ns, $P>0.05$; post hoc Duncan test from Generalized Linear Mixed Models in Table 2, detailed results in Supplementary Table S3).

teria dominated all undecomposed litters. Members of Sphingomonas, thriving in most undecomposed litters, were previously reported as constituents of phyllospheric communities (Purahong et al., 2016), hence presumably occurring in plant leaves prior to senescence. Similar considerations can be drawn for members of Massilia, Methylobacterium, Pantoea, some Pseudomonas, as well as the free-living nitrogen fixing Beijerinckia, that were reported in undecomposed litter as endophytes or epiphytes (Ruinen, 1956; Kutschera, 2007). Most of these genera rapidly disappeared during the early litter decay phase, and only Pseudomonas persisted at relatively high abundance after 30 days of decomposition, which is consistent with some studies reporting that members of this genus can use relatively complex organic substrates (Natsch et al., 1994; Tomasi et al., 1996). In general, most of the cultivable members of Proteobacteria are classified as copiotrophs, i.e. fast growing species that thrive in conditions of high resource availability. Many studies consistently reported a decrease in copiotrophic species during the early stage of litter decomposition, a pattern associated with the depletion of labile organic fractions (Aneja et al., 2006; Keiblinger et al., 2012; Urbanová et al., 2015). In agreement with these observations, the relative abundance of Proteobacteria dramatically decreased during decomposition, a reduction that mirrors the rapid decrease in $O$-alkyl and di-O-alkyl NMR fractions associated with sugars and cellulose. Noteworthy, Proteobacteria almost disappeared in aged, N-poor and aromatic C-rich litter types, such as those of $Q$. ilex and $F$. sylvatica.

At intermediate and late decomposition stages, members of Actinobacteria, Bacteroidetes, and especially Firmicutes became progressively more abundant. Actinobacteria are known as degraders of highly recalcitrant organic materials, including xenobiotic and agrochemicals (Schrijver and Mot, 1999). Within this phylum, Streptomyces was the most abundant genus after 180 days of decomposition. Members of this genus are well-recognized as capable to degrade a variety of recalcitrant substrates, including biopolymers, fats, and aromatic compounds. Consistently, Streptomyces was especially abundant in aged litter of $F$. sylvatica, $P$. halepensis and $Q$. ilex, rich in aromatic C fractions. Moreover, Streptomyces members were not found in litter of nitrogen-fixing species (i.e. C. emerus and R. pseudoacacia), regardless of their content in aromatic fractions.

After 180 days of decomposition, Firmicutes were the most abundant phylum in five out of ten litter types, highly prevailing in C. emerus, $F$. sylvatica, $P$. halepensis and $Q$. ilex litters. In general, members of this phylum are considered resistant to fluctuations in resource availability and environmental conditions, including desiccation (Battistuzzi and Hedges, 2009). Interestingly, for aged litters, we observed a negative correlation between the relative abundance of Firmicutes and the substrate $\mathrm{C} / \mathrm{N}$ ratio, $\mathrm{O}$-alkyl and di-O-alkyl fractions, and a positive association with the relative content of $C$ that resonate within the 46-60 ppm spectral region. Such spectral region is commonly associated to methoxyl C, characteristic of lignin (Incerti et al., 2017), but it can also include overlapping signals of $\mathrm{N}$-alkyl C, as those from aminoacids and polypeptides (Bonanomi et al., 2011). Within Firmicutes, Bacillus and Paenibacillus were the most abundant genera in all aged litter types. Members of these two genera share common trophic strategies, being able to degrade complex polymers by hydrolytic exoenzymes. Moreover, some Paenibacillus and Bacillus species can also degrade chitin, included fungal mycelium (Pleban et al., 1997; Singh et al., 1999). In this regards, our results suggest that at late decomposition and successional stages, some members of Firmicutes, likely belonging to Paenibacillus and Bacillus genera, may feed over mycelial by-products from early colonizing fungi.

In a recent study, reporting the occurrence of several nitrogen-fixing bacteria, including Frankia, Rhizobium and Bradyrhizobium, over decomposed F. sylvatica litter, Purahong et al. (2016) suggested that such functional guild might contribute to increase $\mathrm{N}$ availability during the decomposition process, hence promoting the activity of other microbes. Here, we found that nitrogen-fixing bacteria occurred both in undecomposed and 30-days aged litters. Free-living nitrogen-fixing Beijerinckia were exclusively present in fresh litter, disappearing later on. Rhizobium was rare in fresh and 180-day aged litters, but widespread in all 30 days old materials, with the exceptions of those showing the highest $\mathrm{N}$ concentration (A. mollis and C. emerus). On the other hand, Rhizobium was particularly abundant in litter species with low $\mathrm{N}$ con- 

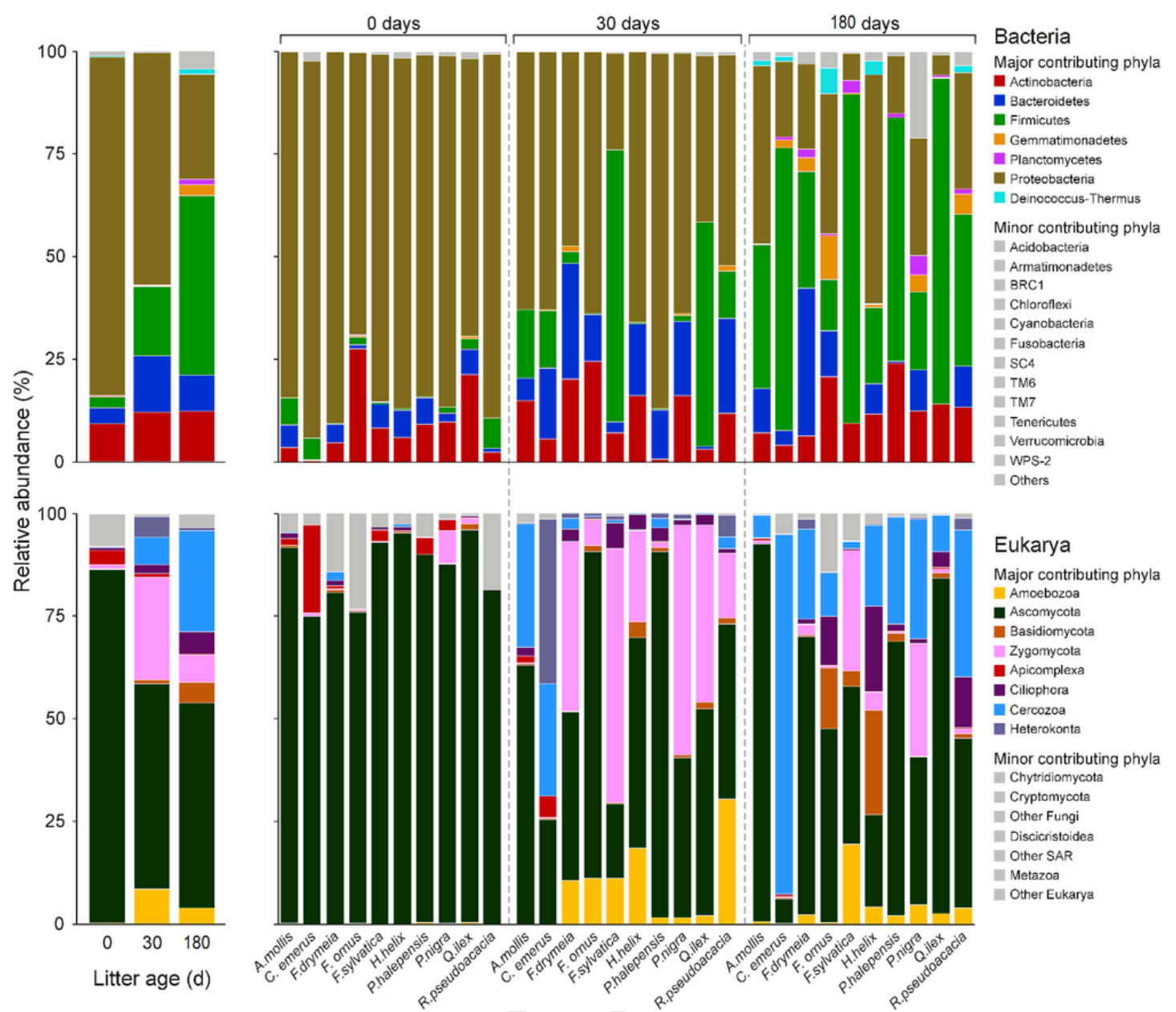

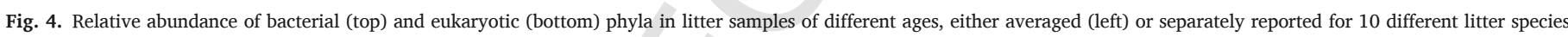
(right).

tent, such as $P$. halepensis, where it even persisted after 180 days of decomposition. These results suggest that nitrogen-fixing bacteria have optimal fitness for early-decomposed litter, and are excluded from ecological niches with very $\mathrm{N}$-rich plant tissues. Further studies are needed to assess if Rhizobium activity might alleviate microbial $\mathrm{N}$ starvation and, then, promote the decomposition of N-poor litter (Bonanomi et al., 2017).

\subsection{Eukarya successional dynamics}

Among Eukarya, fungi belonging to the Ascomycota phylum were dominant in undecomposed litter. In detail, Aureobasidium, a typical phyllospheric genus (Andrews et al., 2002), was the most abundant on all fresh litter types, with the exception of $Q$. ilex, where it was replaced by Aspergillus, suggesting a competitive exclusion between these two taxa. However, Aureobasidium did not occur after 30 days of decomposition, being replaced by zygomycetes and other ascomycetous fungi. According to previous culture-based studies carried-out on different trees species, the persistence of Aureobasidium and other phyllospheric fungi in decomposed litter is uncommon because of their limited competitive capabilities (Osono, 2002; Jumpponen and Jones, 2009; Voříšková and Baldrian, 2013). Differently, Zygomycota were rare in fresh litter but then showed a peak of abundance after 30 days of decomposition, with Rhizomucor and Rhizophus being the most abundant genera. This pattern is consistent with the classic successional theory (Hudson, 1968; Frankland, 1998), predicting that these fast growing, opportunistic fungi are abundant limited to the early phase of decom- position, when the labile $\mathrm{C}$ fraction is still available in decaying litter. Consequently, this functional guild has often been referred as "sugar fungi" because of their marked preference for substrates rich in simple carbohydrates (Hudson, 1968; Osono and Takeda, 2001). Accordingly, we observed an abrupt decrease of "sugar fungi" abundance after 180 days of decomposition, corresponding to the depletion of the litter $\mathrm{O}-$ and di-O-alkyl C fractions. Expectedly, "sugar fungi" were replaced by cellulolytic and ligninolytic fungi. However, we observed some species-specific responses, as in the case of Rhizophus, which was still relatively abundant after 180 days in $F$. sylvatica and $P$. nigra litters, or Aspergillus and Zygomycota, which rapidly disappeared from the labile C - and N-richest litters of C. emerus and A. mollis. Strong competition among "sugar fungi" and bacteria in these nutrient-rich and fast-decomposing substrates could be a possible explanation for our observations.

Aged litters were dominated by Aspergillus and, limited to some cases of slow- (i.e. F. drymeia and P. nigra) and fast-decomposing litter (i.e. $H$. helix) with low relative content of the carboxylic $\mathrm{C}$ fraction, characterized by the occurrence of Basydiomycota, in particular the genus $\mathrm{Co}$ prinopsis. It is known that basydiomycota with ligninolytic activity are characteristic of late stages of litter decomposition, as described in different previous reports (e.g. Vořišsová and Baldrian, 2013; Purahong et al., 2016). In this respect, our study, being limited to an observation period of six months, cannot capture the complete fungal succession as related to litter chemistry dynamics at long term, suggesting the need for prolonged, longitudinal, multispecies experiments to reveal the link between specific litter molecular traits and the occurrence and persistence of climax microbial communities. 


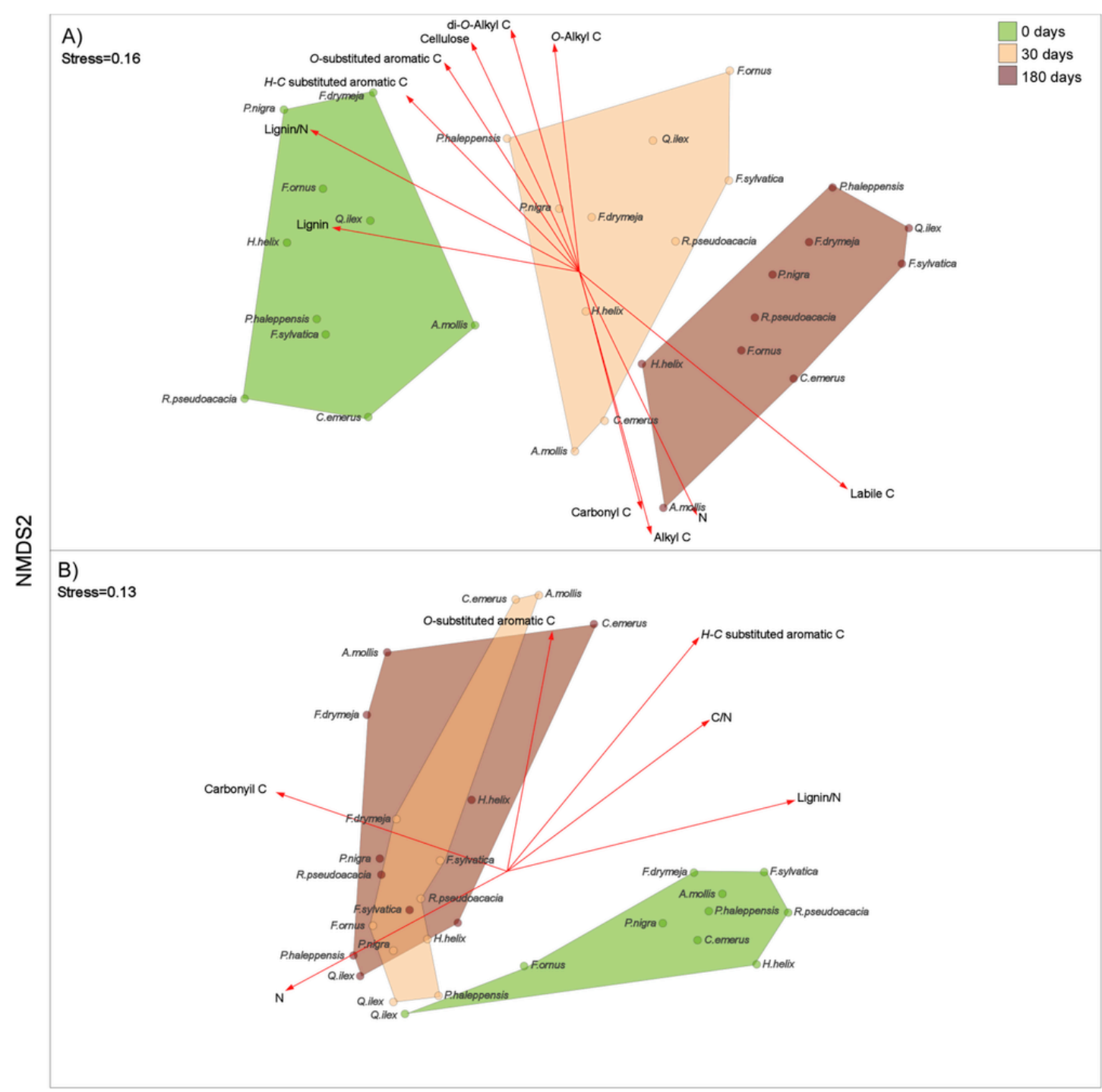

NMDS1

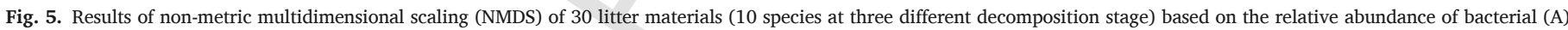
and eukaryotic (B) phyla found in the samples. Litter quality parameters were also plotted, based on vector loadings.

Our analysis, addressing the entire eukaryotic community, highlights a previously unnoticed but widespread occurrence of protists, mainly belonging to the Amebozoa and Cercozoa groups, in decomposed litter. Protists play a crucial role in soil, affecting plant growth and architecture, as well as the carbon and nitrogen cycles (Bonkowski, 2004). Acting as bacterial grazers, protists can shape the soil bacterial communities (Rønn et al., 2002; Rosenberg et al., 2009). Most current knowledge of protistan communities derives from soil studies (Gast et al., 1996; Geisen et al., 2014), with a lack of information on decomposing litter. Our study showed that Acanthamoeba and Cercozoa protists are absent in fresh leaves, but widely distributed in aged litter. Moreover, protistan communities are non-randomly structured, showing strikingly distinct composition in relation to litter chemistry. In general, the peak in protist abundance observed after 30 days of decomposition is probably due to the trophic availability of bacterial prey, but such pattern presented specific exceptions. For instance, Acanthamoeba, a genus with few described species, but widespread in soil samples (Fiore-Donno et al., 2016), was abundant in all litters, but not found in the labile $\mathrm{C}$ - and N-richest $A$. mollis and $C$. emerus materials, where it was completely replaced by Cercozoa. The reasons and processes underlying such species-specific association between protists and litter are unknown, but it could well be hypothesized an indirect effect of litter molecular quality, directly affecting the quality of the bacterial food source. More in general, the widespread presence and the relatively high abundance of protists in all litter types suggest that such microbes could play an important role in shaping litter bacterial community, consistently to soil communities (Rønn et al., 2002; Rosenberg et al., 2009), in turn affecting the decomposition dynamics. Further work is needed to clarify the trade-off between the top-down control of protists on bacterial community, and the bottom-up effect of litter molecular quality and the associated bacterial dynamics on protists community.

\subsection{Linking litter chemistry to microbial succession}

In general, it is generally established that microbial decomposition changes litter chemistry and that such chemical shifts further drive microbial turnover, and hence successional trajectories (Hättenschwiler et al., 2005; Moorhead and Sinsabaugh, 2006; Chapman et al., 2013). However, current knowledge of the specific association between litter molecular properties and microbiota is limited, since most previous studies were based on either single litter types (e.g. Tláskal et al., 2016), or broad descriptors of microbial community response, such as 
A

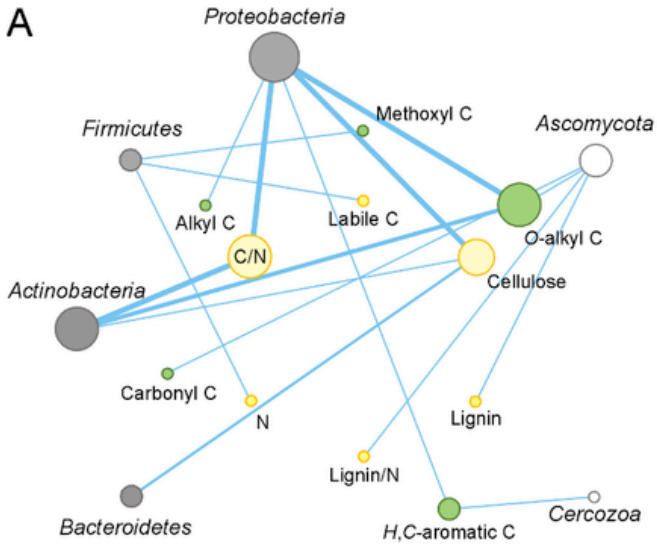

C

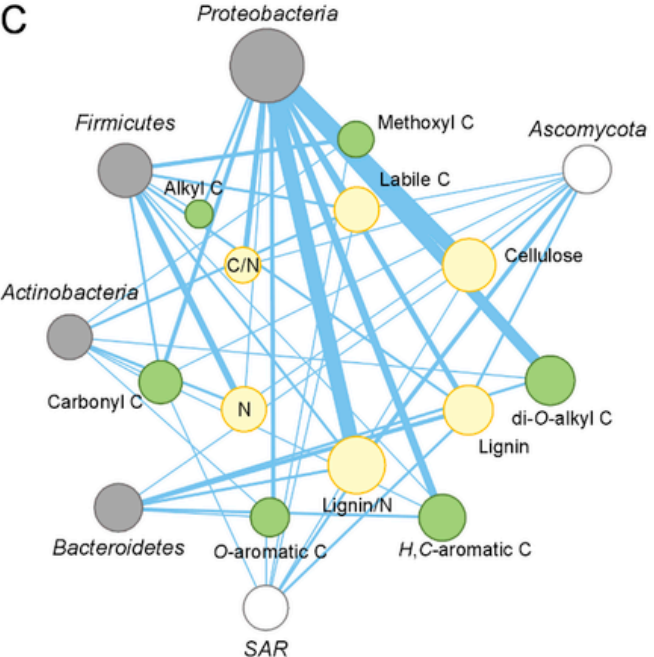

E

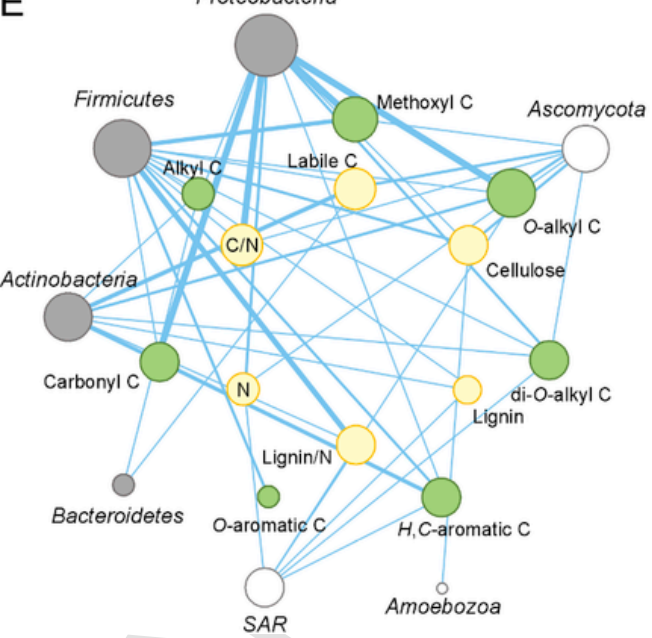

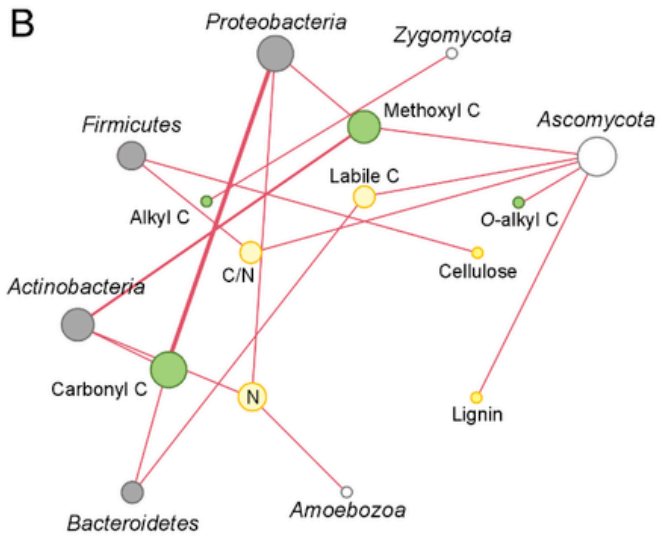

D

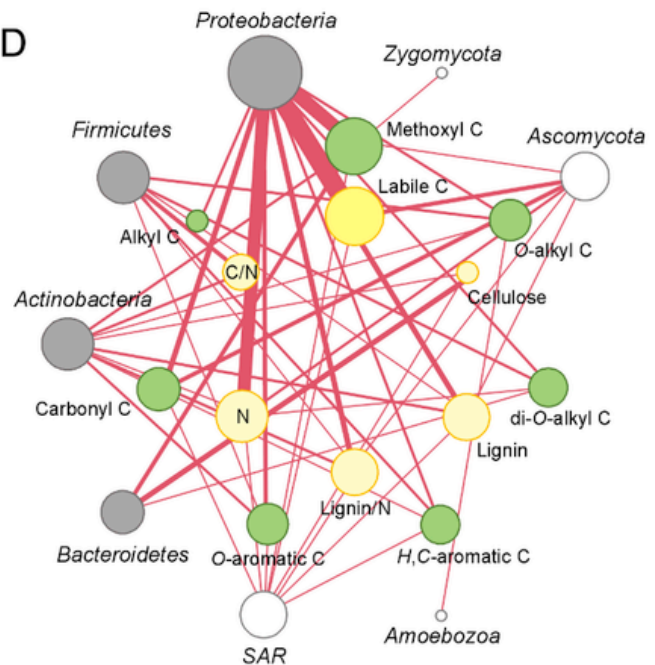

$\mathrm{F}$

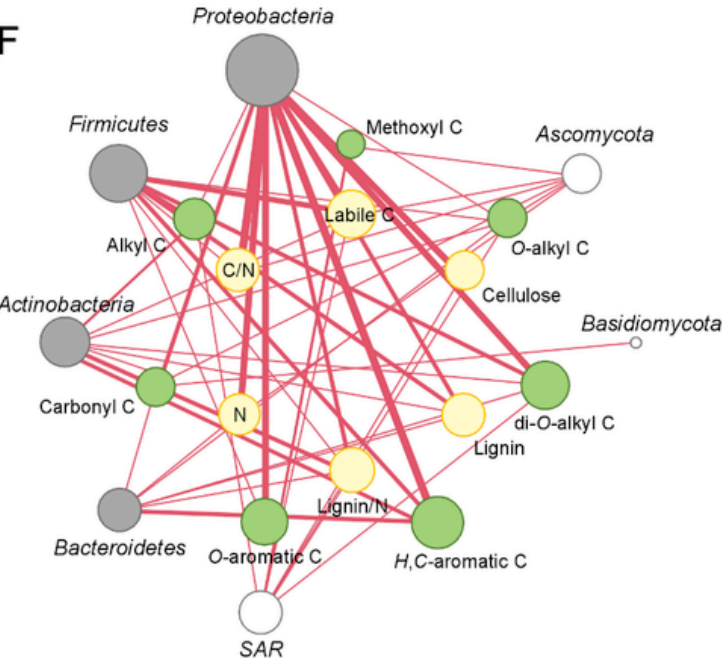

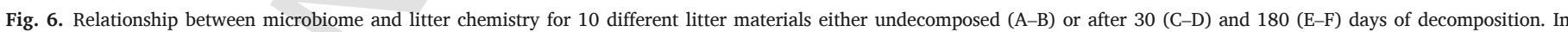

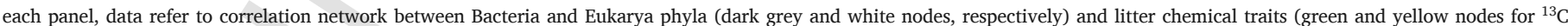

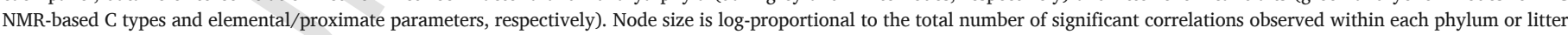

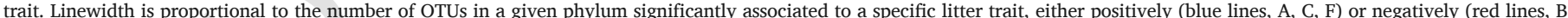

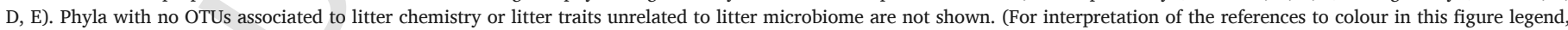
the reader is referred to the Web version of this article.)

heterotrophic respiration or phospholipid fatty acid profiles . Differently, in our study, most litters showed qualitatively similar but quantitatively different chemical shifts while ageing, producing specific effects on microbial communities. According to previous evidence (Preston et al., 2009; Bonanomi et al., 2018b), our ${ }^{13} \mathrm{C}$ NMR analysis revealed the expected progressive depletion of labile $\mathrm{C}$, but also the interesting persistence of more stable molecular fractions. The quality of such litter component changed during decomposition, due to microbial transformation of pre-existing organic molecules into novel recalcitrant 
compounds, as well as selective preservation of the resistant fraction of plant leaf materials. These processes, common to all substrates, proceeded with different rates in different litter species, (e.g. very rapid for fast decomposing litter like A. mollis, C. emerus, H. helix and slow for $F$. sylvatica, $P$. halepensis, $Q$. ilex), according to the broad range of litter molecular properties selected for this study. As such, using large and diverse sets of materials could help to highlight the interconnections between litter chemistry, and diversity and composition of the decomposing microbiota.

We found that the impact of litter chemistry on microbial community structure increased during the decomposition process, being of little relevance in the case of freshly fallen leaves, but becoming the most important controlling factor in aged litter. Indeed, our correlation network analysis identified only 28 significant associations between the microbial community and undecomposed litter chemistry parameters, suggesting that the biotic interactions play a major role in selecting bacterial and fungal endophytes (Bulgarelli et al., 2012). For undecomposed litter, however, $\mathrm{C} / \mathrm{N}$ ratio, cellulose content and the carboxylic and $O$-alkyl C fractions of the ${ }^{13} \mathrm{C}$ NMR spectra appeared as the most important chemical parameters.

On the other hand, the number of significant associations identified by our network analysis dramatically increased to 95 after 30 days, and to 94 after 180 days. In addition, we interestingly found a shift in the association direction (i.e. from positive to negative correlation or vice versa) for several chemical parameters going from 30 to 180 days old litters, indicating a complex, dynamically changing interdependence between litter chemistry and microbiota composition. For instance, after 30 days of decomposition, members of Proteobacteria were generally positively associated to litter lignin/ $\mathrm{N}$ ratio and negatively with the carboxylic C fraction. However, such relationships shifted their sign after 180 days. Considering the set of litter chemistry parameters considered in this study, proximate cellulose, labile $\mathrm{C}$ content and lignin/ $\mathrm{N}$ ratio were those associated to most OTUs, while litter $\mathrm{C} / \mathrm{N}$ ratio was apparently much less predictive of microbiota dynamics.

Considering ${ }^{13} \mathrm{C}$ NMR parameters, $O$-alkyl, carboxylic and methoxyl $\mathrm{C}$ fractions were those associated to most OTUs at early decomposition stage, whereas at later stages aromatic, alkyl and di-O-alkyl C fractions played the utmost roles. For instance, decomposer microbiota in undecomposed litter was unrelated to the $O$-aromatic C fraction, while after 180 days of decomposition the litter content of such molecular type was negatively associated with several bacterial groups (i.e. Firmicutes, Bacteroidetes, and Proteobacteria), positively with Actinobacteria and protists, and unrelated to Fungi. The increasing frequency of association between aromatic compounds and litter microbiota as decomposition was proceeding is consistent with the progressive accumulation in litter of organic aromatic molecules (Berg and McClaugherty, 2008; Preston et al., 2009). In this respect, previous studies on different litter functions, in relation to molecular characterization by ${ }^{13} \mathrm{C}$ NMR, showed that dynamic variations of specific spectral signals can be highly predictive of decomposition rates (Bonanomi et al., 2013), particularly for already decomposed materials, thus capturing the impact of $\mathrm{C}$ molecular quality on microbiota composition. This study confirms the usefulness of describing litter molecular quality by ${ }^{13} \mathrm{C}$ NMR, providing new insights towards the understanding of the complex link between litter quality and the associated microbiota.

\section{Conclusions}

Our study showed that decomposing litter undergoes significant chemical transformations with associated microbiological successional shifts. Despite the wide chemical range of litter materials purposely selected for our decomposition experiment, most litter types remarkably shared similar molecular changes and successional trajectories. A such, our findings suggest a common pattern in the microbial community compositional response to the chemical changes that occur during decomposition. Within this general framework, we could also identify litter-specific successional patterns associated with specific chemical fingerprinting revealed by ${ }^{13} \mathrm{C}$ NMR analysis. In this regards, the combination of ${ }^{13} \mathrm{C}$ NMR analysis with high-throughput sequencing provides a new approach to reveal the complex interconnections between the substrate chemical changes and the microbial community shaping that co-occur during litter decomposition.

\section{Appendix A. Supplementary data}

Supplementary data to this article can be found online at https:// doi.org/10.1016/j.soilbio.2018.11.013.

\section{References}

Aerts, R., 1997. Climate, leaf litter chemistry and leaf litter decomposition in terrestrial ecosystems: a triangular relationship. Oikos 439-449.

Andrews, J.H., Spear, R.N., Nordheim, E.V., 2002. Population biology of Aureobasidium pullulans on apple leaf surfaces. Canadian Journal of Microbiology 48, 500-513.

Aneja, M.K., Sharma, S., Fleischmann, F., Stich, S., Heller, W., Bahnweg, G., Munch, J.C., Schloter, M., 2006. Microbial colonization of beech and spruce litter-influence of decomposition site and plant litter species on the diversity of microbial community. Microbial Ecology 52, 127-135.

Battistuzzi, F., Hedges, S., 2009. In: Hedges, S.B., Kumar, S. (Eds.), Eubacteria. The Timetree of Life. pp. 106-115.

Bäumler, A.J., Sperandio, V., 2016. Interactions between the microbiota and pathogenic bacteria in the gut. Nature 535, 85

Benjamini, Y., Hochberg, Y., 1995. Controlling the false discovery rate: a practical and powerful approach to multiple testing. Journal of the Royal Statistical Society: Series B 289-300.

Berg, B., McClaugherty, C., 2008. Plant Litter: Decomposition, Humus Formation and Carbon Sequestration, second ed. Springer-Verlag, Berlin, Heidelberg.

Bhatnagar, J.M., Peay, K.G., Treseder, K.K., 2018. Litter chemistry influences decomposition through activity of specific microbial functional guilds. Ecological Monographs 88, 429-444.

Bonanomi, G., Cesarano, G., Gaglione, S.A., Ippolito, F., Sarker, T., Rao, M.A., 2017. Soil fertility promotes decomposition rate of nutrient poor, but not nutrient rich litter through nitrogen transfer. Plant and Soil 412, 397-411.

Bonanomi, G., Incerti, G., Barile, E., Capodilupo, M., Antignani, V., Mingo, A., Lanzotti, V., Scala, F., Mazzoleni, S., 2011. Phytotoxicity, not nitrogen immobilization, explains plant litter inhibitory effects: evidence from solid-state ${ }^{13} \mathrm{C}$ NMR spectroscopy. New Phytologist 191, 1018-1030.

Bonanomi, G., Incerti, G., Cesarano, G., Gaglione, S.A., Lanzotti, V., 2015. Cigarette butt decomposition and associated chemical changes assessed by ${ }^{13} \mathrm{C}$ CPMAS NMR. PLoS One 10, e0117393.

Bonanomi, G., Incerti, G., Giannino, F., Mingo, A., Lanzotti, V., Mazzoleni, S., 2013. Litter quality assessed by solid state 13C NMR spectroscopy predicts decay rate better than $\mathrm{C} / \mathrm{N}$ and Lignin/N ratios. Soil Biology and Biochemistry 56, 40-48.

Bonanomi, G., Lorito, M., Vinale, F., Woo, S.L., 2018a. Organic amendments, beneficial microbes, and soil microbiota: toward a unified framework for disease suppression. Annual Review of Phytopathology 56, 1-20.

Bonanomi, G., Incerti, G., Abd El-Gawad, A.M., Cesarano, G., Sarker, T.C., Saulino, L., Lanzotti, V., Saracino, A., Rego, F.C., Mazzoleni, S., 2018b. Comparing chemistry and bioactivity of burned vs. decomposed plant litter: different pathways but same result? Ecology 99, 158-171.

Bonkowski, M., 2004. Protozoa and plant growth: the microbial loop in soil revisited. New Phytologist 162, 617-631.

Bulgarelli, D., Rott, M., Schlaeppi, K., van Themaat, E.V.L., Ahmadinejad, N., Assenza, F., Rauf, P., Huettel, B., Reinhardt, R., Schmelzer, E., 2012. Revealing structure and assembly cues for Arabidopsis root-inhabiting bacterial microbiota. Nature 488, 91.

Caporaso, J.G., Kuczynski, J., Stombaugh, J., Bittinger, K., Bushman, F.D., Costello, E.K., Fierer, N., Pena, A.G., Goodrich, J.K., Gordon, J.I., 2010. QIIME allows analysis of high-throughput community sequencing data. Nature Methods 7, 335.

Chapman, S.K., Newman, G.S., Hart, S.C., Schweitzer, J.A., Koch, G.W., 2013. Leaf litter mixtures alter microbial community development: mechanisms for non-additive effects in litter decomposition. PloS One 8, e62671.

Cornwell, W.K., Cornelissen, J.H., Amatangelo, K., Dorrepaal, E., Eviner, V.T., Godoy, O., Hobbie, S.E., Hoorens, B., Kurokawa, H., Pérez-Harguindeguy, N., 2008. Plant species traits are the predominant control on litter decomposition rates within biomes worldwide. Ecology Letters 11, 1065-1071

Cotrufo, M.F., Wallenstein, M.D., Boot, C.M., Denef, K., Paul, E., 2013. The Microbial Efficiency-Matrix Stabilization (MEMS) framework integrates plant litter decomposition with soil organic matter stabilization: do labile plant inputs form stable soil organic matter?. Global Change Biology 19, 988-995.

De Filippis, F., La Storia, A., Blaiotta, G., 2017. Monitoring the mycobiota during Greco di Tufo and Aglianico wine fermentation by 18S rRNA gene sequencing. Food Microbiology 63, 117-122.

Ercolini, D., De Filippis, F., La Storia, A., Iacono, M., 2012. "Remake" by high-throughput sequencing of the microbiota involved in the production of water buffalo mozzarella cheese. Applied and Environmental Microbiology 78, 8142-8145.

Fiore-Donno, A.M., Weinert, J., Wubet, T., Bonkowski, M., 2016. Metacommunity analysis of amoeboid protists in grassland soils. Scientific Reports 6, 19068. 
Frankland, J.C., 1998. Fungal succession—unravelling the unpredictable. Mycological Research 102, 1-15.

Gartner, T.B., Cardon, Z.G., 2004. Decomposition dynamics in mixed-species leaf litter. Oikos 104, 230-246.

Gast, R.J., Ledee, D.R., Fuerst, P.A., Byers, T.J., 1996. Subgenus systematics of Acanthamoeba: four nuclear $18 \mathrm{~S}$ rDNA sequence types. The Journal of Eukaryotic Microbiology 43, 498-504.

Geisen, S., Fiore-Donno, A.M., Walochnik, J., Bonkowski, M., 2014. Acanthamoeba everywhere: high diversity of Acanthamoeba in soils. Parasitology Research 113, 3151-3158.

Gessner, M.O., 2005. Proximate lignin and cellulose. In: Graca, M.A.S., Bärlocher, F., Gessner, M.O. (Eds.), Methods to Study Litter Decomposition. A Practical Guide. Springer Verlag, The Netherlands, pp. 115-120.

Harper, J., Webster, J., 1964. An experimental analysis of the coprophilous fungus succession. Transactions of the British Mycological Society 47, 511-530.

Hättenschwiler, S., Tiunov, A.V., Scheu, S., 2005. Biodiversity and litter decomposition in terrestrial ecosystems. Annual Review of Ecology, Evolution and Systematics 36, 191-218.

Hudson, H., 1968. The ecology of fungi on plant remains above the soil. New Phytologist 67, 837-874.

Incerti, G., Bonanomi, G., Giannino, F., Cartenì, F., Spaccini, R., Mazzei, P., Piccolo, A., Mazzoleni, S., 2017. OMDY: a new model of organic matter decomposition based on biomolecular content as assessed by 13C-CPMAS-NMR. Plant and Soil 411, 377-394.

Jumpponen, A., Jones, K., 2009. Massively parallel 454 sequencing indicates hyperdiverse fungal communities in temperate Quercus macrocarpa phyllosphere. New Phytologist $184,438-448$

Keiblinger, K.M., Schneider, T., Roschitzki, B., Schmid, E., Eberl, L., Hämmerle, I., Leitner, S., Richter, A., Wanek, W., Riedel, K., 2012. Effects of stoichiometry and temperature perturbations on beech leaf litter decomposition, enzyme activities and protein expression. Biogeosciences 9, 4537-4551.

Kögel-Knabner, I., 2002. The macromolecular organic composition of plant and microbial residues as inputs to soil organic matter. Soil Biology and Biochemistry 34, 139-162.

Kutschera, U., 2007. Plant-associated methylobacteria as co-evolved phytosymbionts: a hypothesis. Plant Signaling \& Behavior 2, 74-78.

Mathers, N.J., Jalota, R.K., Dalal, R.C., Boyd, S.E., 2007. ${ }^{13}$ C-NMR analysis of decomposing litter and fine roots in the semi-arid Mulga Lands of southern Queensland. Soil Biology and Biochemistry 39, 993-1006.

Mazzoleni, S., Bonanomi, G., Incerti, G., Chiusano, M.L., Termolino, P., Mingo, A., Senatore, M., Giannino, F., Cartenì, F., Rietkerk, M., Lanzotti, V., 2015. Inhibitory and toxic effects of extracellular self-DNA in litter: a mechanism for negative plant-soil feedbacks?. New Phytologist 205, 1195-1210.

McDonald, D., Price, M.N., Goodrich, J., Nawrocki, E.P., DeSantis, T.Z., Probst, A., Andersen, G.L., Knight, R., Hugenholtz, P., 2012. An improved Greengenes taxonomy with explicit ranks for ecological and evolutionary analyses of bacteria and archaea. The ISME Journal 6, 610

Melillo, J.M., Aber, J.D., Muratore, J.F., 1982. Nitrogen and lignin control of hardwood leaf litter decomposition dynamics. Ecology 63, 621-626.

Moorhead, D.L., Sinsabaugh, R.L., 2006. A theoretical model of litter decay and microbial interaction. Ecological Monographs 76, 151-174.

Natsch, A., Keel, C., Pfirter, H.A., Haas, D., Défago, G., 1994. Contribution of the global regulator gene gacA to persistence and dissemination of Pseudomonas fluorescens biocontrol strain CHA0 introduced into soil microcosms. Applied and Environmental Microbiology 60, 2553-2560.

Newell, K., 1984. Interaction between two decomposer basidiomycetes and a collembolan under Sitka spruce: grazing and its potential effects on fungal distribution and litter decomposition. Soil Biology and Biochemistry 16, 235-239.

Osono, T., 2002. Phyllosphere fungi on leaf litter of Fagus crenata: occurrence, colonization, and succession. Canadian Journal of Botany 80, 460-469.
Osono, T., Takeda, H., 2001. Organic chemical and nutrient dynamics in decomposing beech leaf litter in relation to fungal ingrowth and succession during 3-year decomposition processes in a cool temperate deciduous forest in Japan. Ecological Research $16,649-670$.

Pleban, S., Chernin, L., Chet, I., 1997. Chitinolytic activity of an endophytic strain of Bacillus cereus. Letters in Applied Microbiology 25, 284-288.

Preston, C.M., Nault, J.R., Trofymow, J., 2009. Chemical changes during 6 years of decomposition of 11 litters in some Canadian forest sites. Part 2. 13C abundance, solid-state 13C NMR spectroscopy and the meaning of "lignin". Ecosystems 12, 1078-1102.

Purahong, W., Wubet, T., Lentendu, G., Schloter, M., Pecyna, M.J., Kapturska, D., Hofrichter, M., Krüger, D., Buscot, F., 2016. Life in leaf litter: novel insights into community dynamics of bacteria and fungi during litter decomposition. Molecular Ecology 25, 4059-4074.

Quast, C., Pruesse, E., Yilmaz, P., Gerken, J., Schweer, T., Yarza, P., Peplies, J., Glöckner, F.O., 2012. The SILVA ribosomal RNA gene database project: improved data processing and web-based tools. Nucleic Acids Research 41, D590-D596.

Rinkes, Z.L., Weintraub, M.N., DeForest, J.L., Moorhead, D.L., 2011. Microbial substrate preference and community dynamics during decomposition of Acer saccharum. Fungal Ecology 4, 396-407.

Rønn, R., McCaig, A.E., Griffiths, B.S., Prosser, J.I., 2002. Impact of protozoan grazing on bacterial community structure in soil microcosms. Applied and Environmental Microbiology 68, 6094-6105.

Rosenberg, K., Bertaux, J., Krome, K., Hartmann, A., Scheu, S., Bonkowski, M., 2009. Soil amoebae rapidly change bacterial community composition in the rhizosphere of Arabidopsis thaliana. The ISME Journal 3, 675

Ruinen, J., 1956. Occurrence of Beijerinckia species in the 'phyllosphere'. Nature 177, 220

Sarker, T.C., Incerti, G., Spaccini, R., Piccolo, A., Mazzoleni, S., Bonanomi, G., 2018. Linking organic matter chemistry with soil aggregate stability: insight from ${ }^{13} \mathrm{C}$ NMR spectroscopy. Soil Biology and Biochemistry 117, 175-184.

Schneider, T., Keiblinger, K.M., Schmid, E., Sterflinger-Gleixner, K., Ellersdorfer, G., Roschitzki, B., Richter, A., Eberl, L., Zechmeister-Boltenstern, S., Riedel, K., 2012. Who is who in litter decomposition? Metaproteomics reveals major microbial players and their biogeochemical functions. The ISME Journal 6, 1749.

Schrijver, A.D., Mot, R.D., 1999. Degradation of pesticides by actinomycetes. Critical Reviews in Microbiology 25, 85-119.

Singh, P.P., Shin, Y.C., Park, C.S., Chung, Y.R., 1999. Biological control of Fusarium wilt of cucumber by chitinolytic bacteria. Phytopathology 89, 92-99.

Spaccini, R., Piccolo, A., Haberhauer, G., Gerzabek, M., 2000. Transformation of organic matter from maize residues into labile and humic fractions of three European soils as revealed by ${ }^{13} \mathrm{C}$ distribution and CPMAS-NMR spectra. European Journal of Soil Science 51, 583-594.

Swift, M.J., Heal, O.W., Anderson, J.M., 1979. Decomposition in terrestrial ecosystems. In: Studies in Ecology, vol. 5, Blackwell Scientific Publications, Oxford.

Taylor, B.R., Parkinson, D., Parsons, W.F., 1989. Nitrogen and lignin content as predictors of litter decay rates: a microcosm test. Ecology 70, 97-104.

Tláskal, V., Voříšková, J., Baldrian, P., 2016. Bacterial succession on decomposing lea litter exhibits a specific occurrence pattern of cellulolytic taxa and potential decomposers of fungal mycelia. FEMS Microbiology Ecology 92, fiw177.

Tomasi, G., Scandola, M., Briese, B.H., Jendrossek, D., 1996. Enzymatic degradation of bacterial poly (3-hydroxybutyrate) by a depolymerase from Pseudomonas lemoignei. Macromolecules 29, 507-513.

Urbanová, M., Šnajdr, J., Baldrian, P., 2015. Composition of fungal and bacterial communities in forest litter and soil is largely determined by dominant trees. Soil Biology and Biochemistry 84, 53-64.

Voříšková, J., Baldrian, P., 2013. Fungal community on decomposing leaf litter undergoes rapid successional changes. The ISME Journal 7, 477. 